\title{
Política, cultura e hegemonia na sociedade civil: uma leitura gramsciana
}

Wilson da Silva Santos

Professor da Universidade do Estado da Bahia

\section{Resumo}

Este artigo tem o objetivo de analisar a relação entre política, cultura e hegemonia em Gramsci. Para tanto, o presente trabalho parte da ideia gramsciana segundo a qual é na construção da hegemonia que se desenvolve a formação ético-política norteada dentro da coletividade, favorecendo ao sujeito a compreensão crítica de si, dentro de uma luta de hegemonias políticas, de direções contrastantes, a princípio no campo da ética, depois da política, para chegar a uma elaboração superior da concepção do real.

Palavras-chave: Cultura; Gramsci; Hegemonia.

\begin{abstract}
This article aims to analyze the relationship between politics, culture and hegemony in Gramsci. To this end, the present work starts from the Gramscian idea according to which it is in the construction of hegemony that the ethical-political formation guided within collectivity develops, encouraging the subject's self-critical understanding within a struggle of political hegemonies, of contrasting directions, at first in ethics, then in politics, in order to reach a higher elaboration of the conception of the real.
\end{abstract}

Keywords: Culture; Gramsci; Hegemony. 
$\mathrm{U}$

ma das análises copiosas que Gramsci realizou nos seus escritos foi o tema da subjetividade, consonante com a sua concepção gnosiológica, fundada na totalidade, na historicidade e na contradição. A subjetividade gramsciana é um legado terminante que cotiza para o desenvolvimento do marxismo. Conceitos salutares, encerrados no seu trabalho, confluem, direta ou indiretamente, com a questão da subjetividade. Isso é indubitável ao perceber a sua preocupação com a reforma moral e intelectual, com os princípios educativos, com a escola e as outras entidades de difusão da cultura, com os elementos ideológicos e com a formação de uma nova visão de sociedade ético-político-econômica traçada pelo sujeito-coletivo das camadas populares e trabalhadoras.

A relevância do ético-político, nos postulados de Gramsci, dimana da aproximação da filosofia idealista de Croce. Segundo Gramsci, Croce

chamou energicamente a atenção para o estudo dos fatos da cultura e do pensamento como elementos de domínio político, para a função dos grandes intelectuais na vida dos Estados, para o momento da hegemonia e do consenso como forma necessária do bloco histórico concreto. A história ético-política é, portanto, um dos cânones de interpretação histórica que deve sempre estar presente no exame e no aprofundamento do desenvolvimento histórico, se se quiser fazer história integral, e não histórias parciais ou exteriores (GRAMSCI, 1999, p. 283).

Essa proximidade à filosofia de Croce opera-se numa dimensão dialética, que alude, no seu cerne, ao distanciamento de análise e compreensão do conceito ético-político. Refutando todo o lineamento idealista desta filosofia, Gramsci situa o homem enquanto sujeito de ação no plano de imanência da história; outrossim, concebe a filosofia da práxis como uma expressão da subjetividade da realidade, no escopo de

transformá-la, interpretando-a como fato histórico, como 'subjetividade histórica dum grupo social', como fato real, que se apresenta como fenômeno de 'especulação' filosófica, enquanto na verdade é um ato prático, a forma dum conteúdo concreto social e o modo de conduzir o conjunto da sociedade a forjar-se em unidade moral (GRAMSCI, 1999, p. 297). 
Gramsci objeta tanto o idealismo, com seus elementos abstrativos e especulativos da história, quanto o materialismo determinístico e mecanicista. Ao contrapor-se a essas duas interpretações, ele concentra o seu perquirir analítico nas mudanças efetuadas na sociedade, através da dimensão ético-política, mas sempre ligada, tal dimensão, aos condicionantes sociais e, sobretudo, aos conflitos sociais. Portanto, a filosofia da práxis, subjetivando a realidade, assenta-se nos fatos históricos, cujas relações sociais acontecem a partir do trabalho socialmente organizado.

$\mathrm{Na}$ perspectiva da totalidade histórica, as atividades humanas ocorrem, consecutivamente, na estrutura das relações sociais, o que denota que o enfoque material e o "espiritual" são uma simbiose, o "uno-plural" do homem real, cuja ação é demarcada no espaço e no tempo, objetivando-se, em suas contradições, a construção da práxis emancipadora ${ }^{1}$. Desse modo, a história ético-política sucede como exteriorização da ação dos sujeitos livres, conscientes e criativos, voltada para a criação do projeto hegemônico político, sócio-cultural e econômico das classes subalternas. Nesse ímpeto, com a maturação da criticidade e a vivacidade da subjetividade, as massas, $a$ priori desagregadas e diluídas nos seus interesses econômico-corporativos, passam a criar gradativamente uma concepção orgânica e superior de sociedade que insurge contra a visão hegemônica da classe dominante.

Assim, a transição do estado econômico-corporativo para o estado ético-político é o processo cartático que

indica a passagem do momento meramente econômico (ou egoístico-passional) ao momento ético-político, ou seja, a elaboração superior da estrutura em superestrutura na consciência dos homens. A estrutura de força exterior que oprime o homem, que o assimila a si e o torna passivo se transforma em meio de liberdade, em instrumento para criar uma nova forma ético-política, em

\footnotetext{
1 “A expressão práxis refere-se, em geral, a ação, a atividade, e, no sentido que the atribui Marx, à atividade livre, universal, criativa e auto-criativa, por meio da qual o homem cria (faz, produz), e transforma (conforma) seu mundo humano e histórico e a si mesmo; atividade específica ao homem, que o torna basicamente diferente de todos os outros seres. Nesse sentido, o homem pode ser considerado como um ser da práxis, entendida a expressão com o conceito centro do marxismo, e este como a 'filosofia' (ou melhor, o 'pensamento') da 'práxis'” (BOTTOMORE, 2001, p. 292).
} 
fonte de novas iniciativas. Assim, a determinação do momento 'cartático' torna-se, no meu entender, o ponto de partida para toda a filosofia da práxis (GRAMSCI, 1999 , p. 314 e 315$)$.

Esse momento cartático de mudança individual e social do sujeito, da passagem da necessidade para a liberdade, faz com que haja uma produção orgânica da sociedade, propiciando a ligação dialética do econômico com as forças sócio-culturais e políticas das camadas populares. Demonstra, essa concepção ético-política, um processo circunscrito na história, no qual as massas buscam expandir a sua atuação política e desenvolver a sua capacidade intelectual e ética, aspirando, com isso, a sua organicidade para lograr a hegemonia. Desse jeito, no projeto políticohegemônico, o ético-político e o econômico devem emanar da filosofia da práxis, superando o dogmatismo e a especulação, representados no equívoco do corporativismo-economicismo. Além disso, o processo cartático éticopolítico, ao ser dissociado dos anseios e valores da sociedade, pode incorrer num diletantismo e numa inconsistência generalizada, justamente por ignorar a particularidade e a complexidade da situação concreta.

Nesse sentido, Gramsci supera tanto Hegel como Croce. Do primeiro, o filósofo italiano rechaça a proposição segundo a qual todos os valores unificam-se no Estado; do segundo, abduz a idéia aristocrática de intelectual, isto é, o idealismo croceano que imputa aos intelectuais a formação do povo. Antagonizando-os, Gramsci julga o momento éticopolítico como a composição de uma nova sociedade elaborada pelas forças políticas das classes subalternas, entremeadas na sociedade civil, espaço este marcado pela autonomia dos sujeitos políticos e pela exteriorização de seus valores, culturas, ideologias e saberes.

A par disso, a sociedade civil, revelada pelo seu movimento aberto à subjetividade e à pluralidade, mostra-se como uma esfera de contradições, de espaço lacunar e de conflitos de interesses. É nesse campo que se presencia o quanto a burguesia arquiteta o seu projeto hegemônico e tenta conservar a estrutura econômica atual; do mesmo modo, as classes trabalhadoras encontram, nesse âmbito, possibilidades para tramar a sua 
associação e unificação, no intuito de confrontar, com seu projeto sociopolítico, a burguesia, disputando e afirmando a hegemonia. Se a sociedade ocidental, com a chegada do sistema capitalista, permitiu a livre iniciativa, a liberdade das relações pessoais sob o esteio da economia de mercado e a regulamentação por força da propriedade privada, ainda assim, provocou, igualmente, a vontade de abjunção das camadas populares e o despontar da democracia direta e participativa circunscrita no social, no político e no econômico. No mesmo território, decisivamente, as diversas lógicas e concepções de sociedade se efetivam. Destarte, as forças das classes subalternas podem operar para suplantar a lógica social vislumbrada e atrelada ao capitalismo; podem ainda apresentar um novo dinamismo de participação das camadas populares e trabalhadoras, assim como uma nova forma de socialização do poder. Em verdade, Gramsci passa a ressignificar os diversos conceitos originados na tradição política burguesa e liberal, tais como: conceito de sociedade civil, de liberdade e, enfim, de concepção de mundo.

Como foi referido, Gramsci eduziu a definição de sociedade civil fundamentalmente de seus principais interlocutores, Hegel, Croce e Marx, convertendo o seu significado para outro sentido. Mesmo mantendo alguns princípios compreendidos na definição do Estado liberal-burguês, como o conceito de liberdade, Gramsci interpreta-o para consignar um conceito eminentemente marxista. Ele direciona seu pensamento para as aspirações e necessidades das classes trabalhadoras; exemplo disso foi a experiência dos Conselhos de Fábrica em Turim, onde verificou a viabilidade de organizar política e socialmente os trabalhadores para o alcance da hegemonia de seu projeto político. Num espaço da fábrica, a vontade coletiva, entremeada em sua subjetividade, tornou-se factível, indo além da lógica de produção industrial do capitalismo e da ligação sociedade civil, industrialismo e capitalismo, difundindo uma nova lógica de produção industrial por meio da participação ativa dos trabalhadores. Esse nexo entre produção econômica e capitalismo 
pode dissolver-se; a exigência técnica pode ser pensada concretamente, separada dos interesses da classe dominante, não só, mas unida aos interesses da classe subalterna. Que uma tal 'ruptura' e uma nova síntese seja historicamente madura é demonstrado peremptoriamente pelo fato mesmo de que tal processo é compreendido pela classe subalterna, que por isso não é mais subalterna, o que mostra suas capacidades de sair de sua condição subordinada (GRAMSCI, 2001, p. 313).

$\mathrm{Na}$ sociedade civil, os sujeitos constroem não apenas a sua subjetividade e as suas potencialidades individuais, mas, de modo igual, desenvolvem as suas ações coletivas. Essa sustentação gramsciana contraria a lógica social liberal, na qual os interesses do indivíduo particular são o ponto fulcral em torno do qual gravita o Estado. Na formação dinâmica, complexa e indissociável "do ser social e do ser particular", está imbuída a visão de sujeito autônomo, que subsiste dentro de uma convivência social concreta, coexistindo aspectos conflitantes e aquiescentes, alicerçada a partir de relações entre indivíduos que apetecem o viver solidário. Isso equivale a dizer que o consenso ativo e a hegemonia são construídos nas diferenças e nos conflitos entre sujeitos sociais conscientes e livres. Dessa forma, a liberdade do indivíduo é pautada e circunspeta de acordo com o ser social; não há em Gramsci a centralidade dos interesses do indivíduo particular enquanto ser independente e transcendental da realidade social. O indivíduo é historicamente original quando apresenta o máximo de valor à 'socialidade', sem a qual seria um 'idiota' (no sentido etimológico, que na prática não se afasta do sentido vulgar e comum). O interesse de Gramsci é aludir que indivíduo e sujeito-coletivo estão imbricados numa relação dialética em que a liberdade, a subjetividade inventiva e a espontaneidade não estão desvinculadas da 'socialidade', da necessidade e da disciplina. Por isso, deve-se lutar

para destruir um conformismo autoritário, retrógrado e nocivo, e por meio do desenvolvimento duma personalidade crítica se chegue ao homem-coletivo, é uma concepção dialética difícil de entender para mentalidades esquemáticas e abstratas. Assim como é difícil compreender que possamos sustentar que pela destruição duma máquina estatal se chegue a criar uma 
outra mais forte e complexa (GRAMSCI, 2000b, p. 289 e 290).

Desse modo, a liberdade individual reporta-se ao compromisso e criticidade do homem-coletivo, considerando-o um sujeito sócio-histórico que se inter-relaciona numa sociedade multifacetada e heterogênea, onde busca incessantemente ampliar e desenvolver as suas potencialidades individuais e de organizar-se coletivamente, de forma livre e criativa. A sua capacidade de associar-se é corolário de sua autodeterminação e iniciativa. Por isso, há uma correlação dialética, “comumente incompreensível”, entre o ser particular e o ser social. Sem considerar essa dimensão ontológica, reduz-se o indivíduo a um ser a-histórico e universalístico, assim como se separa a sua subjetividade da trama social concreta, tornando-a especulativa, vaga e contemplativa.

A vida social e as organizações populares não vão de encontro aos interesses individuais e privados, pois "é o público e o social que encontram sua plena realização não mais separada do privado, uma vez que este último se desenvolve organicamente até chegar a se identificar com o primeiro" (BADALONI, 1962, p. 124 apud SEMERARO, 2005, p. 162). A concepção de homem que Gramsci propõe, como ser social livre e ativo, ressoa na existência do Estado liberal-burguês, já que, ao atingir a condição de autogoverno e ao desintegrar a sociedade política, as classes subalternas, formadas como sociedade civil, através dos organismos públicos, organizações coletivas e comitês populares, passam a determinar a economia de acordo com as decisões deliberadas pela sociedade geral. O Estado, “como domínio exterior", dissolve-se à medida que as camadas populares passam a ser o agente principal do fazer ético-político e do fazer econômico. Desse modo, esse arcabouço exterior que é o Estado sucumbese em razão desse liame da organização pública e coletiva com o particular, individual, proporcionando a manifestação e a prática da liberdade, da pluralidade e da criação de valores democráticos radicais cunhados na participação e na socialização do poder. 
O Estado, preconizado por Gramsci, distancia-se da idéia de instância mantenedora de direito jurídico para todos os cidadãos, edificada sob as bases das doutrinas liberais da democracia formal. Contrapondo-se diametralmente a este Estado, Gramsci defende um Estado que dê “personalidade ao amorfo elemento de massa" (GRAMSCI, 1999, p. 110), que propele e promova o desenvolvimento intelectual e moral da população. O seu intento é fazer com que a classe trabalhadora torne-se dirigente político, econômico e cultural: "O valor mais importante não é que o camponês se torne agrônomo ou que o pedreiro vire mestre (geômetra), mas que o cidadão chegue a ser governante" (Ibid., p. 110).

Essas considerações gramscianas estão em consonância com as suas reflexões sobre o homem, concebendo este como "conjunto de relações sociais, bloco histórico de elementos individuais e subjetivos e de elementos de massa e objetivos ou materiais com os quais o indivíduo está em relação ativa" (Ibid., p. 406). Por isso, o indivíduo não é analisado como um ser hermético, e sim reputado na sua dinâmica de mudança, de interação e conflito com os outros sujeitos e com a natureza, a ponto de modificar a si mesmo quando transforma a sociedade com a sua ação.

Esse predicado que Gramsci atribui ao homem consciente e transformador distingue-se decididamente neste trecho:

\begin{abstract}
Alguém dirá que aquilo que cada indivíduo pode mudar é muito pouco em relação às suas forças. Isso é verdade até certo ponto, uma vez que o indivíduo pode associar-se a todos aqueles que querem a mesma mudança, e se essa mudança for racional o indivíduo pode multiplicar-se por um número incalculável de vezes e obter uma mudança ainda mais radical daquela que possa parecer possível à primeira vista. Sociedades das quais o indivíduo pode participar são muito numerosas, mais do que se possa imaginar. É por meio dessas 'sociedades' que ele faz parte do gênero humano (Ibid., p. 406).
\end{abstract}

A importância das associações, como a escola, é plausível ao provocar mudanças substanciais no próprio indivíduo e, também, na sociedade. A força positiva e criativa dessas "sociedades" é somente consignada quando apresenta um projeto racional e coerente de modificação radical da realidade e, da mesma forma, quando atrai para si maior 
consenso. Ao mesmo tempo, abre espaço para a valoração e a conscientização da subjetividade, de modo a potencializar o "ser sujeito e o vir a ser" como portador de transformação. Essas ponderações de Gramsci sobre o homem assemelham-se em muito com os posicionamentos de Marx para quem

só quando o homem real individual absorve em si o cidadão abstrato, e mesmo permanecendo homem individual se torna elemento do gênero humano, tanto em sua vida empírica como em seu trabalho e em suas relações individuais, quando o homem reconheceu as suas forças próprias como forças sociais e as organizou, só então pode-se considerar terminada a emancipação humana (MARX, 1984, p. 45).

Esse juízo marxiano exprime-se, em Gramsci, na proposição sobre o projeto de formação de uma cultura e de uma nova concepção ético-política das classes subalternas, que tentam aglutinar a quase totalidade da sociedade, tornando-se, tal asserção gramsciana, em princípios ativos de conduta, em força ativa de emancipação humana. Isso se verte diretamente na conquista das liberdades sociais de maneira irrestrita, amparada inexoravelmente na liberdade, na socialização do poder e na capacidade inventiva dos indivíduos.

Este momento ético-político é a superação da fase econômicocorporativa e imediatista, como foi salientado, e também é a superação de outro estágio marcado por interesses econômicos de uma coletividade mais ampliada que, embora centralizada no Estado, tem a intenção de buscar uma “igualdade político-jurídica com os grupos dominantes, pelo fato de reivindicar o direito de participar da legislação e da administração, e até de modificá-las, reformá-las, mas dentro dos quadros fundamentais existentes" (GRAMSCI, 2000b, p. 41). O momento ético-político caracteriza-se por aglutinar não somente os interesses econômicos e administrativos; é também a incorporação, de forma mais aberta possível dentro de uma superestrutura complexa, do projeto político e cultural hegemônico que atravessa toda a sociedade, estabelecendo o consenso político e uma nova ética que inaugurem um novo princípio e uma nova norma ativa da humanidade. 
Portanto, é na construção da hegemonia que se desenvolve a subjetividade, a capacidade de autonomia, a iniciativa individual e a formação ético-política norteada dentro da coletividade. O sujeito obtém a “compreensão crítica de si dentro duma luta de 'hegemonias' políticas, de direções contrastantes - a princípio no campo da ética, depois da política para chegar a uma elaboração superior da própria concepção do real" (GRAMSCI, 1999, p. 103). O indivíduo alarga a sua consciência política e o senso crítico e define a eticidade de sua ação individual e coletiva ${ }^{2}$ nas organizações e instituições engajadas, com a proposta de uma democracia de sociedade diametralmente oposta ao existente, cujo desafio é a formação de valores sócio-políticos das classes subalternas. Realmente, a tomada da hegemonia "representa um grande progresso filosófico, além de políticoprático, porque necessariamente envolve e supõe uma unidade intelectual e uma ética de acordo com uma concepção do real que superou o senso comum e se tornou, ainda que dentro de limites restritos, crítica” (Ibid., p. 104).

A hegemonia, vinculada a um projeto coerente e unitário de gestão democrática e popular e dentro dessa criação ético-política, favorece fundamentalmente a transformação da sociedade. Assim,

a partir do momento em que um grupo subalterno se torna realmente autônomo e hegemônico, suscitando um novo tipo de Estado, nasce concretamente a exigência de construir uma nova ordem intelectual e moral, ou seja, um novo tipo de sociedade e, portanto, a exigência de elaborar os conceitos mais universais, as armas ideológicas mais sofisticadas e decisivas, e a luta por uma cultura superior autônoma, que seja a base ética do novo tipo de Estado (Ibid., p. 225).

Para entendermos o movimento de consenso e dissenso do processo hegemônico, que permeia e determina toda a dinâmica da construção de sentido e ações na sociedade, é necessário, em resoluto, perquirir as reverberações que acontecem entre as produções de valores ético-políticos,

\footnotetext{
${ }^{2}$ Segundo Gramsci, é inconcebível idealizar uma ética individual, pois "o ser humano deve ser entendido como um bloco histórico de elementos puramente individuais e subjetivos e de elementos de massa e objetivos ou materiais com os quais o indivíduo estabelece uma relação ativa" (Ibid., p. 406).
} 
as percepções, as produções ideológicas, as aspirações, as utopias ${ }^{3}$ e a moral com a hegemonia cultural. Na hegemonia, perpassam e interferem as diferentes forças que operam nas diversas esferas sociais, situadas num determinado contexto histórico-social. É um processo cuja dinâmica interna compõe e estabelece manifestações de lutas e altercações, mormente no âmbito cultural e discursivo. Nisso, as relações de poder criam espaços de contradições, o que torna possível a convertibilidade dessa correlação de força no campo das mediações de "domínio material e imaterial”.

A construção da hegemonia requer um processo histórico longo e complexo, que atravessa os diferentes espaços da superestrutura. Carlos Nelson Coutinho salienta que a hegemonia deve ser entendida como "uma batalha cotidiana e a longo prazo, travada no seio das instituições, envolvendo a participação consciente da grande maioria da população" (COUTINHO, 1981, p. 94-96). Daí que a transformação da estrutura sócioeconômica advém de uma revolução cultural que torne as camadas populares e trabalhadoras em sujeitos principais dentro de um movimento racional de emancipação. A conquista da hegemonia, por parte das classes subalternas, exige progressivamente a tomada de posições na sociedade civil, fazendo com que a correlação de forças necessariamente seja alterada, para assumir a direção do Estado.

A construção de novos consensos impõe a desconstrução de uma trama de consensos cristalizados. Essa relação dialética construção/desconstrução, desconstrução/construção concorre para formar fissuras que acontecem nos consensos estabelecidos durante um período histórico pela classe dominante. Isso só é possível com o alargamento das conquistas político-culturais das classes trabalhadoras e populares. Essa correlação de forças engendra a multiplicidade de poderes que atravessa toda a sociedade, ora entremeando-se, ora opondo-se. Dessa forma, a hegemonia apresenta uma imbricação de macro-ações e micro-poderes, de

\footnotetext{
${ }^{3}$ Pode-se dizer que utopia "representa a correção ou a integração ideal de uma situação política, social existente. [...] Torna-se força de transformação da realidade, assumindo corpo e consistência suficientes para transformar-se em autêntica vontade inovadora e encontrar os meios da inovação" (ABBAGNANO, 2003, p. 987).
} 
produção de conhecimento, de cultura, que se desenvolve nas pluralidades, envolvendo a sociedade, os saberes, as culturas e as aprendizagens populares, em ressonância com "princípios" e experiências da prática social concreta, dentro da dimensão de um sistema aberto. Portanto, visa à transformação do existente a partir do próprio existente, para daí gerar o novo. Por isso, a prática de dominação e as relações de poder, que estão intercaladas em todos os espaços, adquirem multifacetados formatos. Há uma multiplicidade de lacunas que leva ao embate de concepções, aumentando, cada vez mais, os dissensos e os conflitos. Os diversos focos de resistência e de luta sobressaem, confrontando o pensamento de que o Estado (sociedade política) centraliza e gera todo o poder, refratário a qualquer vulnerabilidade. Com isso, a maior expansão, na sociedade civil, das forças emancipadoras das classes subalternas divisa políticas sócioeconômicas radicais que sublinhem a inversão das correlações de forças, passando a hegemonia da burguesia para a totalidade dos trabalhadores.

A concepção ético-política de Gramsci não se coaduna com os mitos da religiosidade e com os axiomas da metafísica, cujos postulados da ética baseiam-se na transcendentalidade do homem. A inovação fundamental

introduzida pela filosofia da práxis na ciência da política e da história é a demonstração de que não existe uma abstrata natureza humana, fixa e imutável - conceito que deriva do pensamento religioso e da transcendência -, mas que a natureza humana é o conjunto das relações sociais historicamente determinadas (GRAMSCI, 2000b, p. 56).

Esse pressuposto gramsciano evidencia o ser humano em sua subjetividade, nas relações sociais, como sujeito constituinte e constitutivo do fazer história, distanciando-se de qualquer "especulação filosófica" e de qualquer eticidade abstrata da filosofia tradicional. A sério,

a concepção subjetivista é própria da filosofia moderna na sua forma mais completa e avançada. Dela e como superação dela nasceu o materialismo histórico, que na teoria das superestruturas traduz em linguagem realista e historicista o que a filosofia tradicional expressava de maneira especulativa (GRAMSCI, 1999, p. 131). 


\section{Considerações finais}

Apesar das severas críticas feitas ao ethos burguês, como foi posto anteriormente, Gramsci reelabora alguns conceitos prementes da sociedade moderna liberal, como os conceitos de democracia, subjetividade, valores éticos, igualdade, justiça e a dimensão empírica e concreta da historicidade, isto é, a investigação imanente das condições humanas. Assim sendo, o indivíduo é alicerçado a partir de suas atividades intencionais tanto em suas ações individuais, quanto em ações coletivas, construídas em um campo dinâmico e complexo. Com isso, Gramsci embate a idéia mecanicista e linear da história, segundo a qual toda ação humana é condicionada por uma força sobrenatural, motivando, assim, uma absoluta falta de compromisso. Essa visão pulveriza a autonomia e a atividade inventiva do indivíduo, bem como

todo o sentido de responsabilidade pessoal é submergida dentro duma abstrata e indeterminada responsabilidade social. Se de fato o indivíduo, para mudar, precisa que toda a sociedade mude antes dele, mecanicamente, por quem sabe qual força sobrenatural, nunca aconteceria mudança alguma. A história, ao contrário, é uma luta contínua de indivíduos e de grupos para mudar o que existe numa determinada época, mas para que a luta seja eficiente esses indivíduos e esses grupos precisam se sentir superiores ao existente; educadores da sociedade. $\mathrm{O}$ ambiente, portanto, não justifica, mas só explica o comportamento dos indivíduos, particularmente, dos que são historicamente mais passivos. A explicação até pode servir para sermos indulgentes com o ser humano e fornecerá material para a educação; porém, nunca deve se transformar em 'justificativa', pois isso conduz inevitavelmente a uma das formas mais hipócritas e revoltantes de conservadorismo e de imobilismo (GRAMSCI, 2001, p. 54 e 55).

Essa apreensão do ético-político, impregnado nas relações sociais, rechaça qualquer 'força externa' que possa tomar para si a elaboração de um modelo ético-político de uma sociedade. Nesse sentido, os valores éticopolíticos só podem ser construídos na ação intersubjetiva e na práxis política, sendo vital para tal efetivação a liberdade, a responsabilidade e a 
participação ativa e coletiva das camadas populares. Portanto, são as ações de indivíduos concretos que determinam o conteúdo ético-político do conviver coletivo. Diante disso, as atividades econômicas, que se desenvolvem na infra-estrutura, são compreendidas como atividades situadas numa dinâmica aberta que é originada historicamente e conduzida no âmbito social e ético

quando o 'subalterno' se torna dirigente e responsável pela atividade econômica de massa, o mecanismo a um certo ponto parece um perigo imanente, acontece uma revisão de todo o modo de pensar porque aconteceu uma mudança no modo social de ser. Por que os limites e o domínio da 'força das coisas' são relativos? Por quê? Porque, no fundo, se o subalterno ontem era uma coisa, hoje não é mais uma coisa, mas uma pessoa histórica, um protagonista; se ontem era irresponsável, porque 'resistente' a uma vontade alheia, hoje se percebe responsável porque não é mais resistente, mas agente e necessariamente ativo e empreendedor (GRAMSCI, 1999, p. 106).

A ética, a política, a economia e o conhecimento estão imbuídos na concepção imanente da história. Há uma tensão dialética que mantém essas esferas interligadas, atuando na formação intelectual e moral do indivíduo, não de maneira compartimentada e estanque, mas sim em decorrência de sua coexistência.

A formação intelectual e moral das pessoas significa a tomada da consciência crítica de sua existência e da realidade que ora se apresenta, que embasará a sua ação política para a transformação dessa realidade, irrompendo uma nova lógica e estrutura social e cultural. Essa mudança apresenta-se como um movimento concreto, no qual a dialeticidade entre a realidade objetiva e a formação da subjetividade manifesta-se no confronto das diferentes visões de sociedade.

Assim sendo, a vontade de ação, a disciplina intelectual e a organização dos sujeitos das classes populares, posicionados no contexto histórico-cultural, político e econômico, canalizam-se para o conhecimento de sua existência, cuja finalidade é a construção de um novo projeto de sociedade. Logo, Gramsci não comunga com a idéia segundo a qual as 
transformações desenrolarão com a transformação das estruturas econômico-administrativas de forma mecânica, mas sim através de ação política intencional, que se traduz na criticidade e na eticidade dos indivíduos coletivos e na consubstanciação de uma nova concepção de Estado.

\section{Referências bibliográficas}

ABBAGNANO, N. Dicionário de filosofia. São Paulo: Martins Fontes, 2003.

BLOCH, E. Dialética da esperança. Rio de Janeiro: Paz e Terra, 1974.

BOTTOMORE, T. Dicionário do pensamento marxista. Rio de Janeiro: Jorge Zahar, 2001.

COUTINHO, C. N. Gramsci. Porto Alegre: LP\&M, 1981.

COUTINHO, C. N. Marxismo e politica: a dualidade de poderes e outros ensaios. Rio de Janeiro: Cortez, 1994.

COUTINHO, C. N. Gramsci: um estudo sobre seu pensamento politico. Rio de Janeiro: Civilização Brasileira, 1999.

GRAMSCI, A. Cadernos do cárcere. Introdução ao estudo da filosofia. A filosofia de Benedetto Croce. Ed. e trad. Carlos Nelson Coutinho e Luiz Sérgio Henriques. Rio de Janeiro: Civilização Brasileira, 1999, v. 1.

COUTINHO, C. N. Cadernos do cárcere. Maquiavel. Notas sobre o estado e a politica. Ed. e Trad. Carlos Nelson Coutinho e Luiz Sérgio Henriques. Rio de Janeiro: Civilização Brasileira, 2000b, v. 3.

COUTINHO, C. N. Cadernos do cárcere. Temas de cultura. Ação católica. Americanismo e fordismo. Ed. e Trad. Carlos Nelson Coutinho e Luiz Sérgio Henriques. Rio de Janeiro: Civilização Brasileira, 2001, v. 4.

MARX, K. A Questão judaica. São Paulo: Moraes, 1984.

NOGUEIRA, M. A. Um Estado para a Sociedade Civil: temas éticos e políticos da gestão democrática. 2 ed. São Paulo: Cortez, 2005.

SEMERARO, G. Gramsci e a sociedade civil: cultura e educação para a democracia. $2^{\mathrm{a}}$ ed. Petrópolis, RJ: Vozes, 2005. 